\title{
Tracing facework over time using semi-automated methods
}

\author{
Dawn Archer and Bethan Malory \\ Manchester Metroplitan University / Lancaster University
}

\begin{abstract}
Impolite behaviour tends to attract more evaluative comment than other facework, making it easier to investigate synchronically and diachronically. A reliance on metapragmatic commentary is not optimum for UK parliamentary studies, however, as MPs cannot use "insulting or rude language" that breaks the chamber's "rules of politeness" (http://www.parliament.uk/). The work reported here thus offers three innovative methods of tracing MPs' facework as they negotiated the "unparliamentary language" prohibition, and the results gleaned when the methods were applied to Hansard records (1812-2004). Method 1 prioritises portmanteau tags made up of USAS semtags. Method 2 prioritises themes derived from the HTOED. Method 3 draws on 'meaning constellations' (i.e. simultaneous searches of multiple tags). The UK parliamentary website highlights the "considerable ingenuity" displayed by MPs in order to circumvent their unparliamentary language prohibition. All methods have found examples of such ingenuity, many of which are characterized by multiple facework intentions (Archer 2015).
\end{abstract}

Keywords: facework, Hansard, HTOED, meaning constellations, USAS

\section{Introduction}

The content analysis tool Wmatrix3 (Rayson 2008) enables users to automatically annotate unseen data in a plain text format with 137 CLAWS part-of-speech (POS) categories and 232 USAS semtags representative of different semantic fields. ${ }^{1}$ In recent work combining discourse-analytic and corpuslinguistic methods, Archer (2014) has shown how Wmatrix3 can be used to investigate pragmatic as well as semantic phenomena. For example, it offers users a valuable means of quantitatively investigating verbal aggression semi-automatically - once we target utterances using specific semtags, such as speech acts (Q2.2), "good/bad" evaluation (A5.1+/-), "true/false" evaluation (A5.2+/-), "angry/violent" (E3-), “impoliteness" (S1.2.4-), and "respect/lack of respect" (S7.2+/-). As Archer (2014) concedes, this approach provides 'potential' indicators of verbal aggression only, and, as such, words/phrases captured by semtags must still be viewed in their context-of-use (i.e. re-contextualised 
by the researcher, using an 'expand context' facility within Wmatrix3) so that false positives can be differentiated from genuine instances of verbal aggression.

1.1 Using semantic fields to identify pragmatic spaces over time

Archer's (2014) approach assumes that semantic fields share several similarities with Jucker \& Taavitsainen's (2000) notion of a pragmatic space (of inter-related speech acts). Both are "analysed in relation to neighboring expressions" (Jucker \& Taavitsainen 2000: 74). Both must also allow for possible shifts in sense to enable them to capture different lexical terms (and hence meanings) at a given point in time and over time. In her own study of (late eighteenth-century) Old Bailey trial texts, for instance, Archer (2014) notes a speaker's use of politely to describe the deftness with which he saw a thief pick someone's pocket. As Wmatrix 3 is designed with modern datasets in mind, it cannot cope effectively with such diachronic meaning change. This is less problematic for the Historical Thesaurus Semantic Tagger (HTST), however, ${ }^{2}$ as it incorporates the CLAWS and USAS annotation tools within Wmatrix3 with (i) a VARiant Detector designed to link variant spellings to their modern equivalent (Baron \& Rayson 2008) ${ }^{3}$, and (ii) HT_codes derived from the Historical Thesaurus of the Oxford English Dictionary (HTOED). The VARD helps to eradicate tag mis-assignments due to spelling differences. The HT_codes draw on 700,000 word senses arranged into 225,000 timesensitive categories, thereby ensuring HTST users' annotation results are demonstratively more accurate over time than when reliant on Wmatrix 3 alone.

\subsection{Methodological aims of this paper}

In this paper, we demonstrate three innovative means of analyzing instances of facework semiautomatically using the CQP Web interface of HTST. In doing so, we make use of (Historic) Hansard datasets representative of the first- and/or fourth-quartiles of the nineteenth, twentieth and twentyfirst century. By 'facework' we mean the behavioural masks that a Speaker (S) dynamically coactivated with his or her Addressee(s) (A), when they communicated together in this political context. This requires that we give some consideration to the 'ritual order' or 'interaction order', that is, to "the rules of the group and the [group's] definition" (Goffman 1967: 5-6) of this particular activity type (Levinson 1992). Of relevance here, for example, is a prohibition on "unparliamentary" language use, such that MPs of times past, like MPs today, could "not use insulting or rude language" 
(http://www.parliament.uk/) (discussed further in Section 4.2). Where germane, we should also consider participants' associated feelings in respect to the 'line' taken (Goffman 1967: 4) - whether the purpose was to engage in face enhancement, face aggravation or a combination thereof in context. Archer's (2015) facework scale is useful in this regard. It is based on the assumption that face enhancement represents the positive end of a pragmatic space relating to S's evaluation of A, and face aggravation, the negative end. As Figure 1 reveals, this Goffman-inspired approach is thus designed to capture both face enhancement (achieved using e.g., face enhancing acts or FEAs), face aggravation (achieved using e.g., face threatening acts or FTAs), and everything in-between:

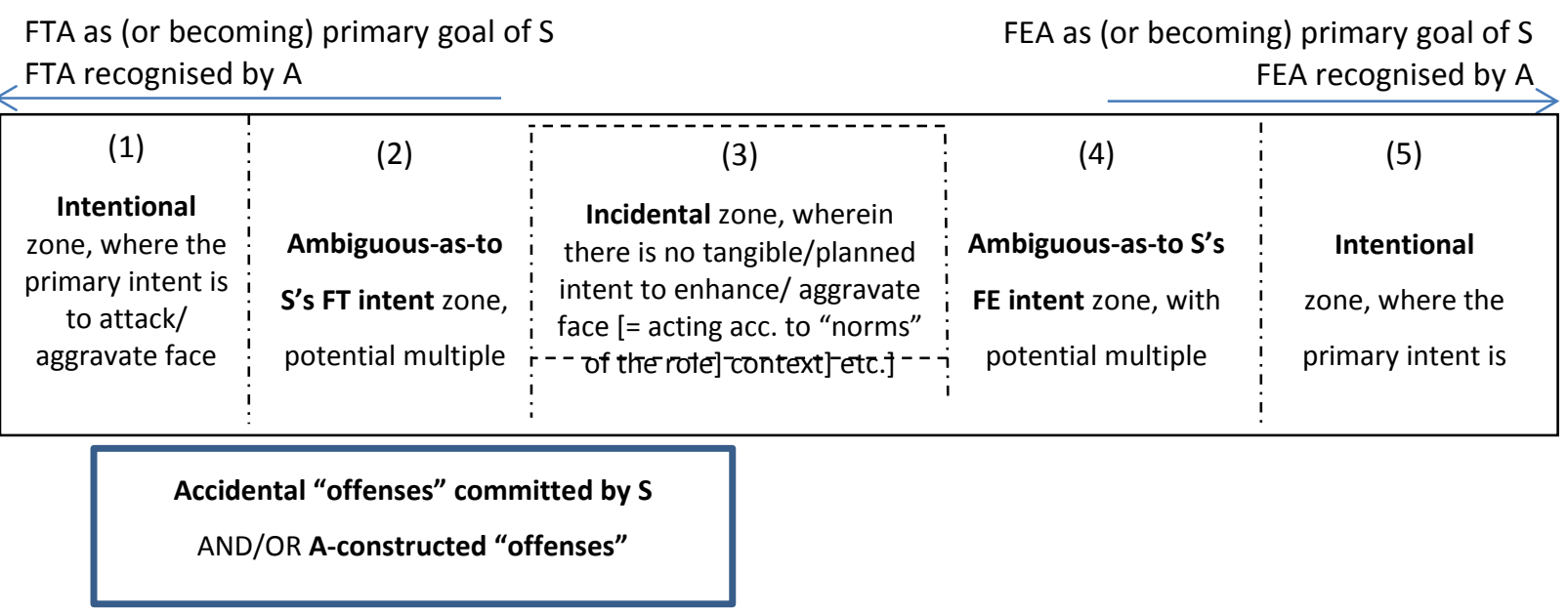

Figure 1. Facework scale, including zone relating to Accidental face threats (adapted from Archer 2015)

In addition to noting the interaction order, and line taken, we might also note the potential faceshaping effect(s) of (i) any previous encounters the participants have had, (ii) any anticipated future encounters yet to happen, and (iii) the societal/ideological beliefs of a given time period. We focus on (iii), and resulting facework tendencies, in Section 2, and explain the (Historic) Hansard datasets (and the activity type they represent) in Section 3. We then go on to demonstrate the results achieved, via the CQP Web interface, when:

(i) Prioritizing semtags joined by portmanteau tags (see Section 4.1);

(ii) Making use of specific HTOED classifications and/or HT codes (see Section 4.2);

(iii)Engaging in 'meaning constellation' searches, that is, simultaneous searches of USAS semtags, CLAWS POS-tags and/or HT codes (see Sections 4.3-4.3.3).

The final sections summarize the insights gained (see Section 5), and work still to do (see Section $6)$. 


\section{Facework from the nineteenth century onwards}

Several features helped to birth a more private focus upon notions of 'self' in the nineteenth century: such that a contemporary's "personality (rather than social rank and roles)" became "increasingly regarded as a, even the, central aspect of the self' (Baumeister 1987: 166, author's italics). They include (but are not limited to) increasing secularisation, the rise of Protestantism (and its focus on individual responsibility), social and geographical mobility, industrialisation, urbanisation, and publications like Smiles' (1859) Self-help. This particular publication is said to have turned notions of self-control, (mutual) self-help, self-discipline and self-respect into virtues for, first, the nineteenthcentury gentleman and, later, the aspiring middle and working classes (Culpeper \& Demmen 2011: 60). Such psychological 'wants' were mirrored, in turn, by an emerging “notion of privacy, of one's private space, [and] of freedom of imposition". This notion relates directly to negative face as first outlined by Brown \& Levinson (1987) - and hence explains Culpeper \& Demmen's (2011: 6) argument that the Victorian Age (1837-1901) offers what is arguably the perfect and only true reflection of this particular politeness model.

As is well known, Brown \& Levinson (1987) postulated that (linguistic) politeness results from a Model Person's attempts to mitigate or compensate for his or her FTAs, and involves strategies which protect A's face when FTAs are likely to occur. Our Model Person may soften requests, complaints or disagreements so that they signal their 'want' to avoid unduly restricting A's freedom of action (negative face) and/or their 'want' to avoid exhibiting an unwarranted lack of approval of A (positive face), for example. In contrast to Brown \& Levinson (1987), Goffman's (1967: 15-26) notions of twentieth-century facework had in mind an avoidance process and an aggressive process involving 'making points', in addition to the corrective process (i.e. a repertoire of strategies which served to counteract 'incidents' or redress them). The ability to make points via deliberate face aggravation tends to be backgrounded by Brown \& Levinson (1987), in spite of their claim that politeness presupposes a "potential for aggression as it seeks to disarm it", thereby making "possible communication between potentially aggressive parties" (Brown \& Levinson 1987: 1). The notion that facework equates to a rational agent purposely choosing a strategy via which to redress any face threat has been heavily criticised in recent years. Indeed, a more common hypothesis today is that, similar to facework today, facework of times past involved S "working out his/her position in a group, understanding the social" as well as cultural and activity-type norms in play at this time "and acting accordingly" (Culpeper \& Demmen 2011: 51). This would mean that facework which was politic (i.e. expected, given the activity type, roles of the participants, etc.) was and possibly still is more 
commonplace than facework which was im/polite (because of failing to meet or superseding what politic behaviour required in terms of mutual face maintenance). Yet, many researchers have argued that twentieth- and twenty-first century British English in particular is characterised by negative, 'non-imposition' politeness. Leech et al. (2009: 88-9) point to a decline in the use of deontic must in the second half of the twentieth century, for instance. According to Farrelly \& Seoane (2012: 393), this decline is indicative of society's "apparently more egalitarian, democratic and antiauthoritarian" approach to facework. In line with this, Wierzbicka (2006: 45-8, our italics) has suggested that twenty-first century speakers of British English tend to frame potentially face-threatening "utterances as (mere) suggestions" so as to avoid "putting pressure" on A. A useful caveat, here though, is Jucker's (2012: 431) observation that "the evidence of non-imposition politeness in Present Day English comes from contexts and situations that can be described as public". As such, future research may yet reveal "that these forms are much less appropriate and less frequent in private situations" or in "certain social classes [or people groups] than in others" (Jucker 2012: 431). The Hansard texts,

explained in Section 3, constitute a public activity type, of course. As will become clear, however, it is one in which speakers do not opt to suggest things only. Indeed, contra Wierzbicka (2006), speakers seem to have deliberately put pressure on others in their political interactions (past and present). Many did so in linguistically creative ways, too, so as to avoid any accusation of "unparliamentary language" use (www.parliament.uk). This included varnishing their face-aggravating acts with 'superficial politeness' (see Sections 4.1-4.3.3).

\section{Explanation of Hansard datasets}

Hansard is both the name by which the official reports of parliamentary proceedings in Britain (and many commonwealth countries) are known and the surname of the publisher who reported British parliamentary debates from $1803 .{ }^{4}$ T.C. Hansard's initial links with parliamentary proceedings were through Cobbett's Weekly Political Register (Reid 2012: 8). When Cobbett suffered severe financial difficulties in 1812, Hansard acquired Cobbett's shares in the newspaper, and promptly changed its title to Hansard Parliamentary Debates. Between 1812 and 1878, the Hansard Parliamentary Debates were in direct competition with Almon \& Debrett's Parliamentary Register (which pre-dated Hansard) and the Mirror of Parliament (1828-43). Its future was cemented, however, when, first, Hansard's press received a subsidy with which to employ reporters (Ward 1980), and second, the absorption of parliamentary reporting by Parliament, in $1909,{ }^{5}$ led to the creation of dedicated teams of official parliamentary reporters and editors in situ (Crewe 2005: 84). 
In this paper, we make use of data drawn from both Hansard Lords and Hansard Commons. Specifically, we look at periods that coincide with the:

(i) War of 1812 (i.e. $1^{\text {st }}$ June 1812-1 ${ }^{\text {st }}$ March 1815);

(ii) 1880 General Election (i.e. $1^{\text {st }}$ April $1879-30^{\text {th }}$ April 1880);

(iii) The First World War (WWI) (i.e. $28^{\text {th }}$ June 1914-28 ${ }^{\text {th }}$ June 1919);

(iv) Winter of Discontent (i.e. $1^{\text {st }}$ July $1978-30^{\text {th }}$ April 1979);

(v) Iraq War (i.e. $23^{\text {rd }}$ September 2002-16 $6^{\text {th }}$ September 2004).

We have opted for periods in the first and/or fourth quartiles of each century, where inter/national social and/or political unrest were known to have taken place. The War of 1812 was fought by the United States against the United Kingdom, its North American colonies, and its American Indian allies. The 1880 General Election saw British Liberal politician William Ewart Gladstone in direct competition with his fierce rival, Conservative Leader Benjamin Disraeli. WWI was a global war centred in Europe. The Winter of Discontent refers to UK-wide strikes by public sector trade unions over ongoing pay caps by the then-Labour government (led by James Callaghan). The Iraq War was a protracted armed conflict, which began with the 2003 invasion of Iraq, led by the United States, and toppled the government of Saddam Hussein. Our snapshot of this particular war has been partly determined by the Hansard coverage made available to us (which ends $16^{\text {th }}$ September 2004), and partly by the publication of the now infamous September Dossier (which falsely claimed that Iraq possessed weapons of mass destruction, and was reconstituting its nuclear weapons programme).

The beginning of our coverage deliberately predates the point at which Hansard records have been protected such that they are not subject to libel claims (see Parliament Papers Act of 1840). We do not mean to imply, by this, that Members have had free reign to say anything they please since 1840. On the contrary, they have had to adhere to strict protocols prohibiting the use of language that is overtly unparliamentary since at least 1844 , when the first parliamentary "rule book" was published (see also Section 4.2). Nonetheless, we are interested in determining whether the facework strategies found within the 1812 dataset were any more or less overtly face-threatening than those found in the later periods (see Section 4.3). Another important observation, in respect to the Hansard records, is that Members' contributions have had to be recorded according to strict parliamentary regulations, since at least the House of Commons Select Committee's proposal of 1907. This proposal allowed for repetitions and redundancies to be omitted and "obvious mistakes" to be "corrected", for example, but demanded that everything else "that adds to the meaning of the speech or illustrates the argument" be maintained (cited in Finch \& Fafinski 2015: 157). As the "full reports" have explicitly stated that 
they are "not strictly verbatim" (Finch \& Fafinski 2015: 157) from 1907, we must nonetheless allow for the possibility of interpretative error on the part of the reporters (see Chilton 2004).

A number of researchers have successfully shown that it is still possible to use these and similar transcripts to investigate facework (as well as other discursive phenomena). Harris (2001: 451) has explored "the discourse of Prime Minister's Question Time” during March to November 2000, for example, and found that "much of it...[wa]s composed of intentional and explicitly facethreatening (or face enhancing) acts". She further suggests that what she calls "systematic impoliteness' (but we call 'intentional face aggravation') was both sanctioned by and also "rewarded in accordance with the expectations of Members of the House" and the "adversarial and confrontational political process" (Harris 2001: 451). This is something to which we return in Section 5. Harris (2001: 454) goes on to stress the importance of judging im/politeness "against a set of expectations" held by the community of practice (Wenger 1998) in question, and of fully appreciating - such that we pay attention to - how these particular "discourse practices [...] have evolved over a long period of time and are still evolving" (cf. Sections 1 and 2). Our focus in the remaining sections of this paper is that of tracing one aspect of this discourse practice - facework - over time, within our political datasets, whilst also remaining sensitive to its inter-relationship with discourse identity and impression management (Goffman 1959). For, as Fetzer \& Bull (2012: 128) observe, “politicians 'do' politics in and through their acts of communication", and, as such, can "be seen both to bring their discourse identities as political agents into a communicative setting, and to bring them out in that setting" for impression management purposes. ${ }^{6}$

\section{Identifying Potential Facework Indicators within the HTST}

Table 1 (below) highlights the degree of 'Potential Facework Indicators' (PFIs) in the Hansard datasets. They were identified (by us) using three innovative methods (all of which make use of the HTST interface, based on CQP Web).

Table 1. Frequency of PFIs returned by search type, and \% relating to facework

\begin{tabular}{llll}
\hline Search type & $\begin{array}{l}\text { PFI hits } \\
\text { returned }\end{array}$ & $\begin{array}{l}\text { Number found to } \\
\text { relate to facework }\end{array}$ & $\begin{array}{l}\text { \% of hits found to } \\
\text { relate to facework }\end{array}$ \\
\hline Portmanteau tag & $2,798,661$ & 332,201 & $11.87 \%$ \\
Single HT code & $2,230,480$ & 386,988 & $17.35 \%$ \\
HT string & 8034 & 3,954 & $49.21 \%$ \\
\hline
\end{tabular}


As the number of hits, per search type, represent potential indicators of facework only (see second column), each hit had to be viewed in its specific context-of-use to enable false positives to be differentiated from true positives. ${ }^{7}$ In our case, between $11.87 \%$ and $49.27 \%$ of the identified PFIs proved to be worthy of further investigation (see final column). These percentages are based upon our manual checking of 1.6 million hits (i.e. $32.7 \%$ of all results returned). Notice that, although all search types are able to find PFIs that turn out to be true positives, the meaning constellation approach is the most effective in this regard (although it produces less PFIs for researchers to check).

The forthcoming sections outline some of the instances of facework identified, using the three methods, and relate those findings to what we already know about facework in that period and/or facework and parliamentary discourse.

\subsection{Portmanteau tag searches}

When a word or multi-word unit has a meaning sense that transcends two (or more) semtags, they are captured as a portmanteau tag (P-Tag) within USAS. Such P-Tags are relatively easy to locate using the CQP Web interface of the HTST and can be very effective when it comes to locating PFIs. Our investigations of the Hansard datasets has revealed, for example, that the "speech act" semtag (Q2.2) provides useful PFIs when used in combination with three of the semtags Archer (2014) drew upon to investigate verbal aggression in the Old Bailey (1783-93). The P-Tag relating to aggressive speech acts (Q2.2/E3-) pointed to 50,694 PFIs, across all Commons and Lords datasets. Between 3\% and $24 \%$ of these PFIs turned out to be true positives (depending on period and/or House), and picked up terms such as threat/s, threaten/ing, threatened and invective. The P-Tag relating to impolite speech acts (Q2.2/S.1.2.4-) pointed to 6,056 PFIs, across our datasets, between 5\% and 50\% of which turned out to be true positives (depending on period and/or House), and picked up terms such as insult/ing, mockery, ridicule/s, sarcasm, sarcastic and taunts. The P-Tag relating to speech acts denoting respect (Q2.2/S7.2+) pointed to 32,487 PFIs, across our datasets, between 4\% and 29\% of which turned out to be true positives (depending on period and/or House), and picked up words such as acclamation/s, flatter/y, praise/s and glorified.

Clearly, not all of the above terms relate to actual speech acts. As such, they need to be recontextualised to determine whether, first, they do 'do facework', and second, that facework constitutes face enhancement, face aggravation or a combination thereof in context (Archer 2015). Consider Example (1) involving glorified, taken from the (Lords) WWI dataset: 
(1) If I may be allowed to say so with great respect to the gentleman who is to be, as I understand, the new Minister, the Minister of Reconstruction is going to be a glorified Under-Secretary of the Prime Minister (S5LV0026P0_00787, 08/08/1917)

S's use of with great respect to the gentleman appears to be an overt (and hence deliberate) instance of his 'doing' deference and respect: in a way that attends to the new Minister's positive face (Brown \& Levinson 1987). However, this third-person instance of face enhancement was part of an if-clause that was immediately followed by S's belittling prediction that the Minister would be no more than $a$ glorified Under-Secretary of the Prime Minister. Example (1) is one of many (historical as well as modern) instances where rhetorical devices co-existed with and sometimes acted as a prelude to a face-aggravating move (cf. Harris 2001: 463, Culpeper 2011: 176). We return to MPs uses of expressive politeness features (Eelen 2001) "to varnish otherwise [face aggravating] acts" (Johnson \& Clifford 2011: 45) in Section 4.3.3.

Within the (Historic) Hansard datasets, we have found it profitable to focus on thirty-three semtags (used as part of a P-Tag). Length constraints prohibit an examination of all possible permutations. Here, then, we illustrate two P-Tags not yet discussed. The first relates to egotistical speech acts (S1.2.3+/Q2.2), of which there were circa 1,635 true positives across all datasets, picking up words such as boast/ed and bragged. The second relates to unethical behaviour typified by falseness or deception (G2.2-/A5.2-), of which there were circa 5,824 true positives across all datasets, picking up words such as cheat/s, cheated, cheating and con. Michael Portillo provides us with at least one of the egotistical speech act (S1.2.3+/Q2.2) examples from the Commons: Portillo stated his knowledge "that the [then] Chancellor like[d] to swagger and boast about the working families tax credit" (S6CV0347P0, 6/04/2000). It served, moreover, as a preface for a rhetorical ifquestion: "if it really [was] the greatest thing since sliced bread, as he claim[ed], why [was] he proposing to abolish it?" The implication, then, was that the Chancellor was vacillating at best and a trickster at worst. Commons examples captured by the unethical behaviour (G2.2-/A5.2-) P-tag included an MP's concern that a fellow MP might have fallen into unparliamentary language use:

(2) I hope that the hon: Member for Stockton, South (Mrs Taylor) will assure the house that she was not accusing the hon: Member for Blaby (Mr: Robathan) of being a cheat, which would be unparliamentary use of language (S6CV0355P0, 2/11/2000).

We explore unparliamentary language use in more detail in the next section. 
HTOED classifications and HT_codes are more fine-grained and time-sensitive than semtags. HTOED classifications are particularly useful when it comes to tracing name-calling (past and present) based on a certain characteristic. Table 2 provides a few of these classifications:

Table 2. HTOED classifications pointing to PFIs related to name-calling

\begin{tabular}{|c|c|c|c|}
\hline $\begin{array}{l}\text { Semantic category } \\
\text { captured }\end{array}$ & HTOED classifica & $\operatorname{ion}(\mathbf{s})$ & $\begin{array}{l}\text { Example terms } \\
\text { (given in HTOED) }\end{array}$ \\
\hline Mental deficiency/Person & 01.02 .01 .02 .01 .03 & 02.01 & Moron \\
\hline Homosexuality/Male & 01.03.02.06.02 & 07.01 & Fairy, faggot, fruit, queer, ginger beer \\
\hline Violent behaviour/Person & 01.05.05.21.05.06 & 02 & Bully, tyrant, yobo, ruffian, hooligan \\
\hline Stupid person/dolt & 02.01.09.06.01 & & Mule, dummy, half-wit \\
\hline Blockhead & & & Moron, bird-brain \\
\hline Lout/oaf & 02.01.09.06.01.01 & & Brute, lubbard, \\
\hline Idiot/crazy person & 02.01.09.06.03 & 04 & Ratbag, ding-a-ling, flake \\
\hline $\begin{array}{l}\text { Want of knowledge/ } \\
\text { ignorance/ignorant person }\end{array}$ & 02.01 .12 .07 & 06 & Know-nothing \\
\hline
\end{tabular}

The UK parliamentary website page relating to unparliamentary language use appears to suggest that such name-calling should be too overt for parliamentary contexts, past or present, as it "breaks the rules of politeness in the House" (www.parliament.uk/). Indeed, it is up to the Speaker of the House to ensure "MPs do not use insulting or rude language and do not accuse each other of lying, being drunk or misrepresenting each other's words". The website goes on to list some words to which the Speaker has taken objection in the past, including "blackguard, coward, git, guttersnipe, hooligan, rat, swine, stoolpigeon and traitor". As well as these terms, terms such as moron also occur in our Hansard datasets: there are thirty-three instances of moron in Commons texts dating from 1937 to 2002, for example, and nine instances of moron in Lords texts dating from 1960 to 1992. Most usages of moron proved to be descriptive: a Member of the Lords pointed out that "Illiteracy does not mean that a person is a moron" (S5LV0340P0, 29/03/1973), for example. However, a few are overt in their face attack - such as when one MP said of another: "The hon. Member is a moron" (S5CV0623P0, 16/05/1960). As we might expect (given the prohibition on unparliamentary language use), this particular usage did not pass without comment. The MP who complained did not immediately focus upon the use of moron though. Instead, s/he informed the Temporary Chairman that "the hon: Member for Leek (Mr: Harold Davies) [...] did not stand up to refer to [...] the Member for Kidderminster as a moron", only then adding that that was "not a correct method of addressing or referring to an hon: Member of this Committee" (our italics). 
The parliamentary website page relating to unparliamentary language concludes by asserting that MPs such as Winston Churchill have often used "considerable ingenuity to get around the rules", for example, calling lies 'terminological inexactitudes' (www.parliament.co.uk/). The most recent usage of moron in our dataset (Example (3) below) is also linguistically creative. Alluding to the Iraqi conflict, an MP comments unfavourably on Britain's relationship with the US:

(3) Genghis Khan was probably sophisticated, but I do not believe that we would want him for an ally: The Foreign Secretary and his colleagues should consider carefully before they appease the United States Administration under President Bush: I am against that because, as Nelson Mandela said, that Government are as dangerous as any other Administration in the world: The sooner the decent people of America, of whom there are so many, are able to elect a President who is not a "moron"; as one Canadian Minister has called Bush; who knows where Iraq is, and who has some ideas behind him, the better it will be for all of us and for the people of Iraq (S5CV0395P1, 25/11/2002).

Most facework studies focus on participants who are directly involved in an exchange, or, to a lesser extent, are the intended audience or the overhearers of an exchange. Yet, the above highlights the importance of investigating face attack - and also face enhancement - which targets another or others who are absent. In this particular case, $\mathrm{S}$ invited As (as well as the public more generally) to infer similarities between George Bush and the brutal Mongol ruler, Genghis Khan, as well as to infer that the then US President was so inept that he did not know where Iraq was. Notice how the MP attributes the assessment of Bush as "a moron" to a (Canadian) Minster, however, in order to give himself a level of plausible deniability, should he be accused of unparliamentary language.

As Table 1 highlighted, single HT_codes were found to point to 2,230,480 PFIs in total. This cumulative total was made up of 1,604,604 PFIs from the Commons datasets and 625,876 PFIs from the Lords datasets. These PFIs included (but were not limited to): ${ }^{8}$

Table 3. Tracing PFIs using single HT_codes

\begin{tabular}{ll}
\hline HT_code & Meaning \\
\hline AO18a & Hostile action/attack \\
AO21d & Lack of violence/severity/intensity \\
AO22c/d & Good or bad behaviour \\
AR21a & Hair-splitting, quibbling \\
AR45g & Bias, in-tolerance, prejudice \\
AS06 & Accusation, charge \\
AS07 & Evaluation, estimation, appraisal \\
AS12b & Respect \\
AS14 & Contempt \\
AS14a & Derision, ridicule, mockery \\
AS14b & Disrespect, disfavour, insult \\
\hline
\end{tabular}




\begin{tabular}{ll}
\hline AS14e & Denunciation, invective \\
AT20 & Spiteful, ill-will \\
AU22 & Displeasure \\
AU23 & Annoyance, vexation \\
AU32 & Hostility, enmity \\
AX24 & Denial, dissent \\
\hline
\end{tabular}

Some of the HT_codes shown in Table 3 more readily unearthed PFIs, which turned out to be genuine instances of facework, than others. For example, $60 \%$ of the PFIs highlighted by the "contempt [...]" HT_code (AS14) in the 1812 Commons dataset (that is, 34 out of 57 hits) proved to be true positives. Similarly, the "disrespect [...]" HT_code (AS14b) pointed to 93 PFIs, 53\% of which turned out to be true positives. These two HT_codes were also useful, when it came to finding true positives in other Commons datasets. The "contempt [...]" HT_code pointed to 8,147 instances in the 1880 Commons dataset, $49 \%$ of which equated to true positives. The "disrespect [...]" HT_code pointed to less instances in the 1880 Commons dataset (i.e. 1,270). Nonetheless, $48 \%$ of these turned out to be true positives. The "contempt [...]" HT_code was not always the most relevant code in all Commons datasets, however. Indeed, the "displeasure [...]" HT_code (AU22) was the most effective at finding true positives in the WWI Commons dataset, uncovering 7,936 PFIs: 53\% of which turned out to be true positives. There were also interesting differences, when comparing results across the Lords and Commons datasets. For example, the "bias [...]" (AR45g) and "derision [...]" (AS14a) HT_codes pointed to more true positives than other HT_codes in percentage terms (i.e. $56 \%$ and $52 \%$ respectively) in the 1880 Lords dataset, but they did not uncover as many PFIs (i.e. only 133 and 84 hits respectively). The PFI with the most hits in the 1880 Lords dataset was, in fact, the "contempt [...]" HT_code - but only $29 \%$ of the 1,243 hits turned out to be true positives. The "contempt [...]" HT_code and the "denial [...]" HT_code (AX24) uncovered more hits than most other codes in the WWI Lords dataset (i.e. 1,146 and 3,192 respectively). Of these, 29\% and 31\% respectively turned out to be true positives. The most effective HT_code in the WW1 Lords dataset, in percentage terms, was the "derision [...]" (AS14a) HT_code, with 63\% of the 131 hits capturing true positives. These - and many of the other results not mentioned here (due to length constraints) - point to the potential of uncovering interesting differences in the facework used, according to House (i.e. Commons versus Lords) and/or according to time period.

Some of the HT_codes, in Table 3, also pointed us to facework which seemed to constitute both face aggravation and face enhancement in practice. Consider Example (4), uncovered using the HT_code relating to "lack of violence/severity/intensity" (AO21d):

(4) My hon: Friend the Member for Brent, South (Mr: Pavitt) was quite right to castigate the right hon Member for Wanstead and Woodford (Mr: Jenkin): He made not even a veiled attack but an open, 
unconcealed attack on the trade unions, separately and collectively: As a sponsored Member, I take very strong exception to those attacks: There is no more responsible or moderate trade union operating within the Health Service than the Confederation of Health Service Employees: It is dedicated to the preservation and improvement of the NHS, and nowhere more so than in the mental health service, the Cinderella of the Service (S5CV0953P000595, 08/03/1966)

S first applauded another MP's castigation of Mr Jenkin, before going on to criticize him personally for his "open, unconcealed attack on the trade unions". This attack of Jenkin's positive face (Brown \& Levinson 1987) was then paralleled by a face enhancement strategy designed to portray one of the trade unions (Jenkin had attacked) in an extremely positive light (i.e. as responsible, moderate, dedicated, etc.).

As highlighted in Section 1, Archer's (2015) facework scale provides a useful means of capturing combinations of face enhancement, face aggravation and everything in-between. This includes facework that is strategically ambiguous when it comes to primary facework intent. The ambiguity arises because the interlocutor's utterance (or utterances), and the facework strategies underpinning it (or them), deliberately serve(s) "more than one goal at the same time" (Penman 1990: 21). As such, it is difficult to determine whether the interlocutor's primary facework goal is that of face enhancement or face aggravation. Consider Example (5):

(5) $[\ldots]$ what exactly does the community desire to do with these men? Does it hope with people of inflexible determination, to make good soldiers of them? That seems to be wildly idealistic: Does it desire to shoot them? If so, the simplest thing is to say so at once and shoot them out of hand, which would cause fewer of these disgraceful scenes: I understood that there was in the Military Service Act a clause which it was stated in another place provided that persons who conscientiously objected to and refused to perform any kind of military service were not liable to be shot [...] (S5LV0020P001931, 04/05/1916)

The Member of Lords's strategy involved asking - before answering - a series of rhetorical questions. In this way, he was able to presuppose that it was "widely idealistic" to assume conscientious objectors could "make good soldiers", but in such a way as to aggravate the face of both those who held such a view and also the "people of inflexible determination" (i.e. conscientious objectors themselves). This two-edged FTA was followed by what is best described as a shock tactic: a suggestion that if "the community...desire[d] to shoot" conscientious objectors, then "the simplest thing" was "to shoot them", thereby limiting the number of "disgraceful scenes". That this was S's own view was then immediately problematized, via the mention of a clause that allegedly prohibited the shooting of conscientious objectors. 
Trilling (1967: 23) has commented that none is "so shockingly personal as that of our own time", when it comes to (the teaching of) literature, because of raising "every question that is forbidden in polite society". PFI hits like Example (5) suggest that the House of Lords was - and remains - an arena where "question[s] [...] forbidden in polite society" have also been raised so that the might be debated. This is especially true of supplementary questions; as, in practice, they need only be tangentially relevant to the first question (Chilton 2004: 93). This may help to explain the high occurrence of strategies, in our (Historic) Hansard datasets, which are strategically ambiguous in facework terms (Archer 2015: see also 4.3.1-4.3.3). In contrast, first "questions requiring an oral response in the chamber" (Chilton 2004: 94) have been highly regulated for some time. They must first be put in writing, for example, and must only relate to matters within a Member's responsibility. They must also be worded so as to avoid "the use of declaratives and the possibility of presupposition, implicatures and invited inference" (Chilton 2004: 95), following Erskine May's insistence that first questions should not seek "an expression of an opinion", contain argument, "inference or imputations" and/or make use of "rhetorical, controversial, ironical or offensive expressions" (cited in May \& Sweetman 1989: 287).

\subsection{Utilising meaning constellations}

As noted in Table 1, meaning constellations proved to be the most effective search type, as they tended to point to more true positives (in percentage terms). The desire to eradicate false positives (i.e. results that do not turn out to be genuine instances of facework) is what partly prompted us to begin simultaneously searching for a combination of (consecutive) HT_codes, or HT_codes plus semtags/POS tags. Simultaneously searching for a contiguous sequence of facework-related tags is not the same as searching for P-tags made up of two or more semtags (see 4.1) or searching for statistical collocates, using measures of association such as mutual information, t-scores and loglikelihood (Dunning 1993); both of which tend to be based at the sentence level only. Rather, we are thinking here of 'meaning constellations' to do with facework, which might transcend sentence boundaries. We consider such meaning constellations to be analogous to a DNA strand. Much like how we reorganise words of the alphabet to create different words, the Adenine/Thymine and Cytosine/Guanine base pairs of a DNA helix determine the information available for building and maintaining a particular organ (i.e. a foot as opposed to a liver). Our hypothesis is that meaning constellations relating to facework function similarly: that is, they are made up of specific combinations of semantic fields and/or parts-of-speech which, when organised in certain ways, can 
be used to signal im/politeness, politic behaviour, strategic ambiguity, and even a combination of face enhancement and face threat (Archer 2015).

We have found a variety of meaning constellations to be useful when searching for PFIs across the five Hansard datasets. Figure 2 identifies eight of the most frequent, when the results are combined for Hansard Commons and Hansard Lords (but see Section 5). These results have been normalised so that they represent instances per million words:

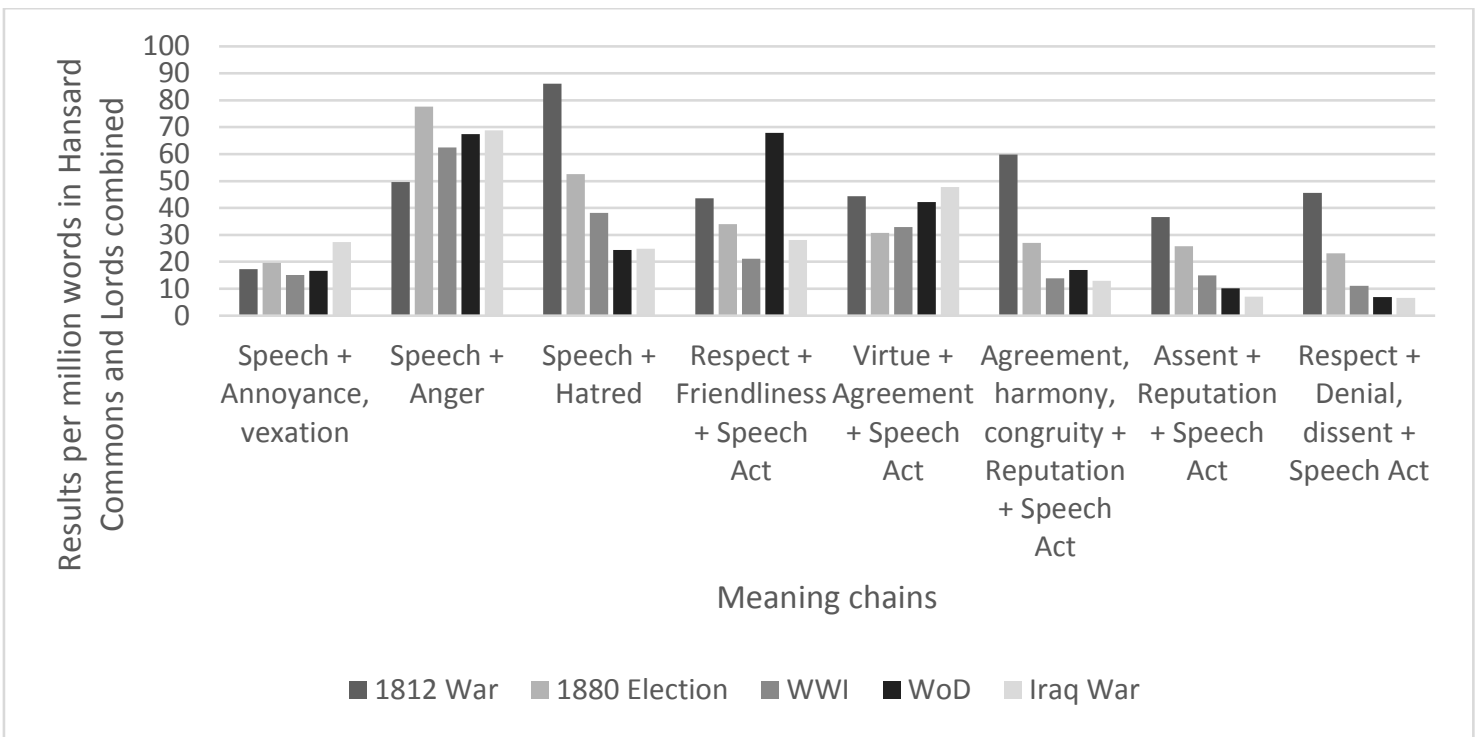

Figure 2. Eight most frequent meaning constellations in Hansard Commons and Lords

As Figure 2 reveals, the "speech and anger" meaning constellation occurred relatively frequently in all of the Hansard datasets (i.e. between 50 and 80 times per million words). Quite a few of the identified PFIs display metapragmatic (or evaluative) commentary, moreover, as in Example (6):

(6) What offends me very deeply is the high-handed, almost Saddamesque way of treating the British constitution: I do not think I have ever been so angry in the 30 years I have been in this House: I love this House: I love the constitution of this country: I love a balanced Whig arrangement: But to be treated like this! (S5LV0649P0_02065, 06/12/2003)

In this instance, the MP overtly highlighted his offence at the way others were "treating the British constitution", before using the neologism Saddamesque to implicate that their behaviour had been near-despotic. The FTA was then counterbalanced by a FEA amplifying the MP's love of the House/Constitution/balanced Whig arrangement (achieved via syntactic parallelism). As the Hansard transcript goes on to report, at least one "Member of the benches opposite" was not impressed with 
the MP's rhetoric, for he met it with a bald-on-record FTA: "Shut up!". The Hansard report signals, further, that this negative face attack was delivered "in a barracking way".

As Figure 2 further reveals, four of the eight most frequent meaning constellations are most frequent in the 1812 dataset (relating to England's war with America). We were surprised to find that the "speech and hatred" meaning constellation was particularly frequent in this first dataset, as it suggests that early nineteenth century MPs were more prepared to signal disgust and animosity than their counterparts from later periods - in spite of the fact that Hansard records were still open to libel claims at this time (cf. Section 3). The three additional meaning constellations to occur more frequently in the 1812 dataset capture attempts at face enhancement, however, and are thus in line with Culpeper \& Demmen's (2011: 51) claim that the Victorian politeness “culture [actually] began evolving a few decades before" the Victorian Age proper. Notice, in addition, that five of our eight most frequent meaning constellations combine HT_codes with the USAS semtag for Speech Acts (Q2.2) (cf. Figure 2). In the sections that follow, we focus on meaning constellations, which share this speech act (Q2.2) characteristic, namely:

(i) "Bad behaviour/accusation/speech act";

(ii) "Accusation/spitefulness/speech act";

(iii)“Respect/commendation, praise/speech act”;

(iv) “Respect/contempt/speech act”.

As the above meaning constellations are not amongst the eight most frequent highlighted in Figure 2, we should highlight that 1-4 have been chosen for two principle reasons. First, to demonstrate the value of paying attention to all meaning constellations (not just the most frequent), given that they all tend to reveal PFIs worthy of further investigation. Second, our initial investigations indicate that meaning constellations made up of semantic fields with a more explicit association with im/politeness (e.g. “(dis)respect”, "praise”, "bad behaviour", "contempt”, etc.) tend to have a higher incidence of true positives than some of the other meaning constellations. The meaning constellations under (i) and (ii) tend to point to PFIs indicative of face threat, for example, albeit sometimes using a veil of superficial face enhancement (see Section 4.3.1). The third meaning constellation tends to point to PFIs indicative of face enhancement. However, on closer inspection, some hits suggested that that face enhancement can come with a "sting in the tail" (see 4.3.2). The fourth meaning constellation points to PFIs typically representative of a combination of face enhancement and face threat (see 4.3.3). This can sometimes render them strategically ambiguous, in facework terms (Archer 2015). 


\subsection{1 (Bad Behaviour), Accusation, (Spitefulness), Speech Act}

As with our aforementioned meaning constellations, the meaning constellation "bad behaviour/accusation/speech act" is most frequent in the 1812 datasets, occurring 7.17 times per million words in the Commons sub-corpus, and 8.18 times per million words in the Lords sub-corpus (see Figure 3).

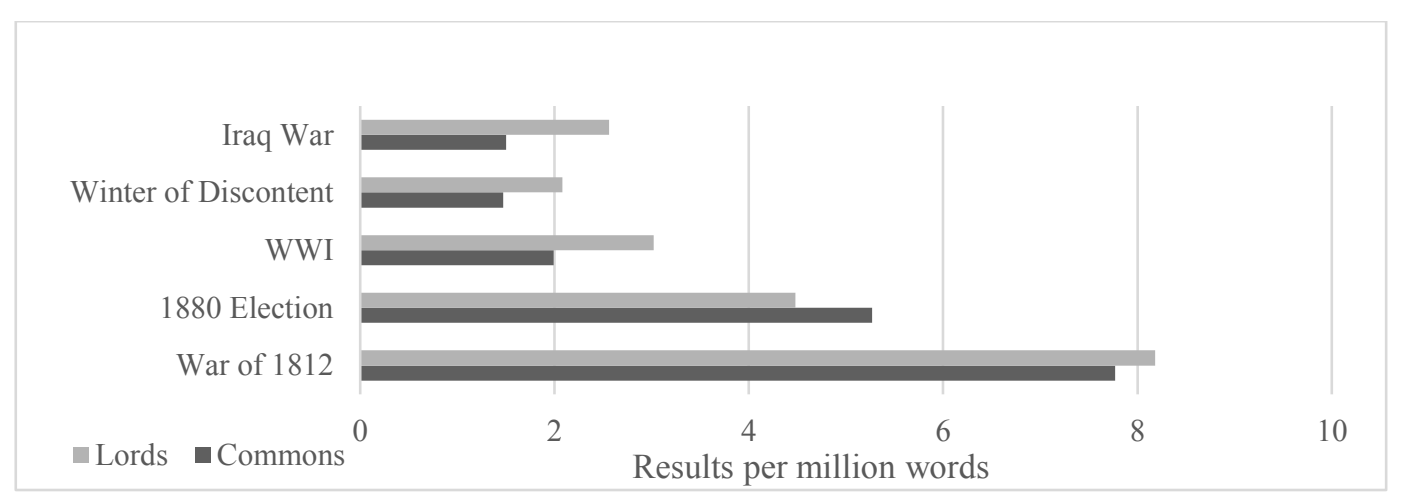

Figure 3. "bad behaviour/accusation/speech act" meaning constellation results

Although the number of results returned is much smaller than the other search types discussed in Sections 4.1 and 4.2, length constraints nonetheless prevent us from exploring examples from each of the five Hansard periods. This said, we have noted a persistent pattern occasioned by the Members' need to address each other by their position and in the third person: that of making use of both position and the third person when doing face attack. In Example (7), taken from the World War I dataset, an MP indirectly accused one of his counterparts in the Commons of bias towards Belgium:

(7) When the hon: Member wants to throw cold water upon the stories of atrocities in Belgium, why he should always drag in his sneers about the Belgian atrocities in the Congo I leave it for the House and country to judge... (S5CV0068P0_01653, 16/11/1914)

There is no attempt to save the face of the Target here. On the contrary, the MP was deliberately framed as someone who knowingly sneered at a time when people were unjustly suffering. In Example (8), in contrast, a Member of the Lords was at pains to point out his belief, via the metarepresentation I do not think (Chilton 2004), that those he spoke of would not consider he was "saying anything discourteous" about them: 
(8) ....as to the merits of the question, I am entirely content with the three speeches which have been made upon this side of the House: It is quite true that those speeches were followed on the other side by two of the most remarkable debaters in Parliament: But I do not think they will consider that I am saying anything discourteous, when I say that they declined to grapple with the real merits of the question, and dwelt upon small points that do not, in the slightest degree, impugn the statements of my noble Friend... (S3V0247P0_04492, 08/07/1979)

In fact, S effectively presented himself as someone who was 'merely doing his job' (i.e. weighing the merits of the arguments of both sides of a debate). If true, the utterance could be claimed to be an instance of politic facework (Watts 2003). Yet, there is a stronger argument for interpreting it as an instance of Cockcroft \& Cockcroft's (2005: 116) persuasion by "concealing or down-playing the interests behind the persuader" and, hence, as a strategically-ambiguous face threat aimed towards the two (albeit remarkable) debaters (Archer 2015). Note how the strength of "the three speeches...upon [his] side of the House" is framed by his being entirely content with them. In comparison, the two debaters (and hence the Opposition) are framed as failing "to grapple with the real merits of the question" or to "impugn the statement of [his] noble Friend" (because of opting to $d$ well upon small points only), inspite of their acknowledged talents when it comes to debating.

As Figure 4 reveals, the "accusation/spitefulness/speech act" meaning constellation also occurs most frequently in the 1812 dataset; although much less frequently than some of the other meaning constellations (i.e. 1009.58 times per million words in the Commons sub-corpus).

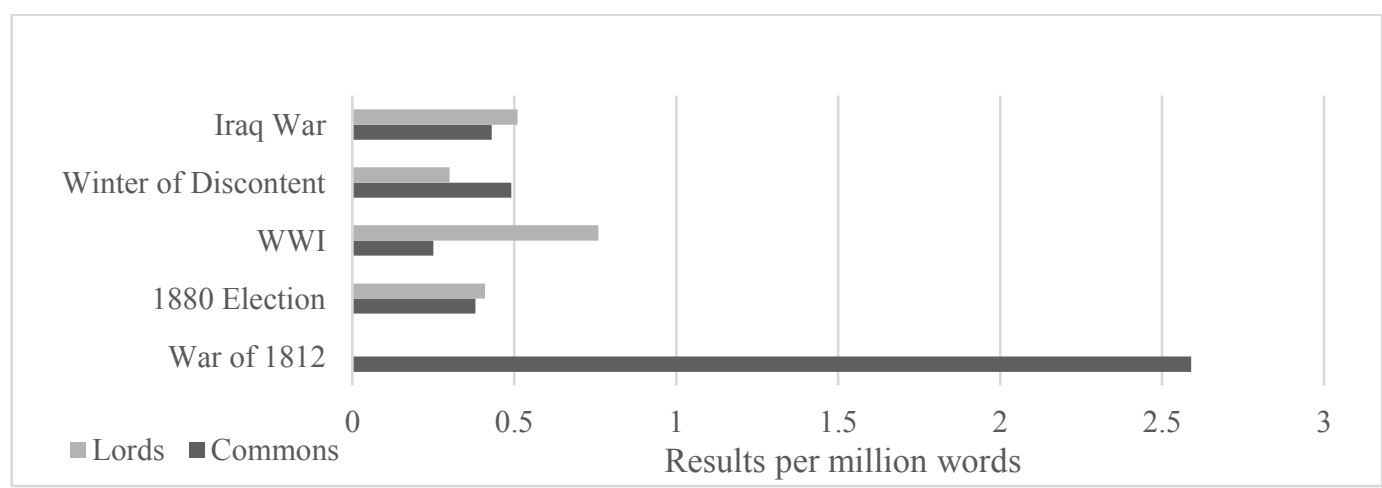

Figure 4. "accusation/spitefulness/speech act" meaning constellation results

In line with the prohibition on unparliamentary language, most of the hits captured in the five datasets are not overtly spiteful at first glance. This does not prevent them from packing a metaphorical punch, however. Example (9) from the Winter of Discontent Lords dataset involves a Member airing a 
"complaint ... against [his own] countrymen" in respect to their inclination "to look at the past rather than the present and the future":

(9) There must, I think, be a taint of original Toryism in Irishmen; they are so inclined to glance back enviously to the good old days, and to take a dismal view of the future (S3V0239PO_0216, $12 / 04 / 1978)$

We have included the above because of how much S's apparent distaste for such a backward-looking view might tell us about his ideological perspective. Indeed, (for him) it seems to represent both a literal looking back to a time past, which his countrymen (erroneously) transmute into "the good old days", and, hence, a potentially retrograde step which hampers (political) progress. This "flaw" is explained, in turn, by correlating Irishmen with original Toryism (thereby signalling S's additional distaste for the latter). It is worth repeating Fetzer \& Bull's (2012: 128) observation, at this point: that “politicians 'do' politics in and through their acts of communication", and, as such, can "be seen both to bring their discourse identities as political agents into a communicative setting, and to bring them out in that setting" for impression management purposes (cf. Section 3).

As the case of Sir David Gore-Booth reveals, unintentional indiscretions - and, hence, instances of 'accidental face damage' (Goffman 1967: 14) - can also afford would-be political opponents the opportunity of (negatively) framing the hapless offender and, by extension, the ideas/ideologies/political party they represent (Chilton 2004: 6-7). Gore-Booth had written a letter to the chief executive of British Aerospace in 1999, when Ambassador to Saudi Arabia. In that letter, he had used references such as "company wives". Eton-educated, 'Old Conservative' Gore-Booth went on to explain to a UK parliamentary Select Committee that the reference equated to "convenient shorthand" only, like "FO [Foreign Office] wives" (Chilton 2004: 7). This explanation did not serve to diminish the offense caused to the British company. Labour MPs Helen Jones and Lynda Clarke, and the Labour chairman Rhodri Morgan, also claimed to be offended: not least because of the implication that the wives in question "in some sense belong[ed] to the company" (Chilton 2004: 7). According to Chilton (2004: 8), "challenging verbal formulations on such grounds is a[n important] part of doing political discourse, as [conversely] is refusing to do so". In the case of the latter, he points to MP's counter-claims such as that's just semantics or you're just being politically correct, where political correctness and semantics are framed (by them) as being undesirable. 


\subsubsection{Respect + Commendation, praise + Speech Act}

As with most of our meaning constellations, "respect/commendation, praise/speech act" was most frequent in 1812 (with 11.65 occurrences per million words in the Commons dataset, and 8.18 occurrences per million words in the Lords).

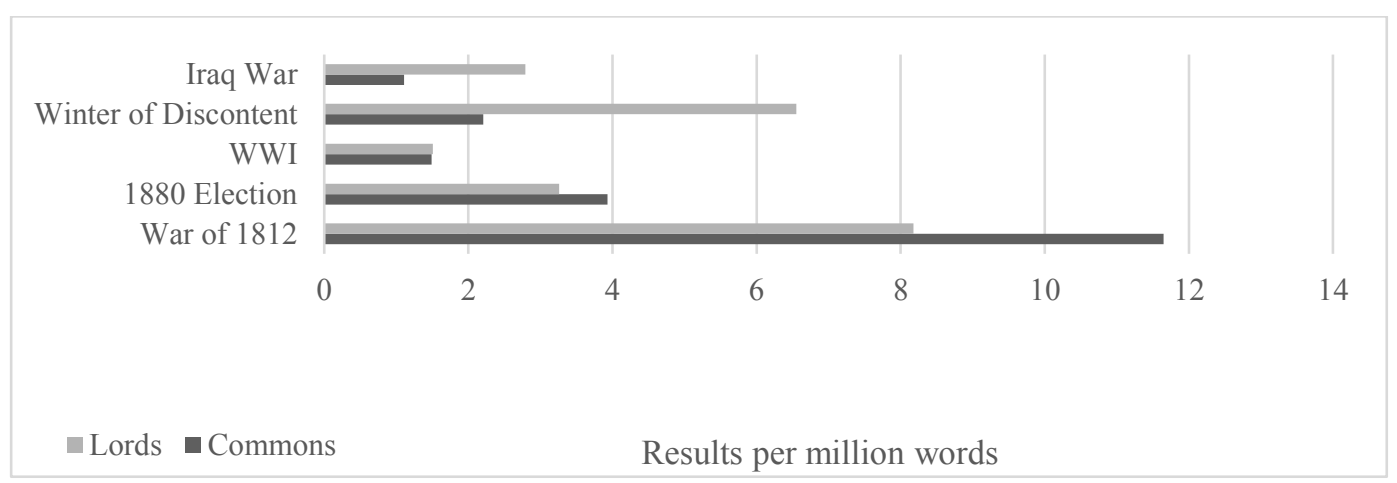

Figure 5. "respect/commendation/speech act" meaning constellation results

Example (10), taken from the 1812 Commons dataset, highlights how an MP:

(10) [...] was sure his noble friend had too much reverence for the ancient monarchical parliamentary constitution of the country, to meditate such an innovation as might lead to the most perilous consequences; to consequences, indeed, which, from the recently disturbed state of the public mind, he could not, he must confess, contemplate without dismay (S1V0024P0_00740, 30/11/1812).

Here, the face enhancement of "having [...] reverence for the" country's parliamentary constitution is merely a prelude to a communicated concern that "an innovation [...] might lead to the most perilous consequences".

The embedding of an FTA within a face-enhancing formulation seems to have been at least as common historically (and perhaps more so) than it is today: thereby suggesting that the strategically-ambiguous facework zone of Archer's (2015) Facework Scale applies from at least 1812 onwards, in this type of dataset. This said, there are instances where the facework goal seems to have been face enhancing (as opposed to face threatening, or simultaneously face enhancing and face threatening). Examples (11) and (12) from the Winter of Discontent and the Iraq War periods (respectively) contain explicit congratulations: 
(11) The Secretary of State and his right honourable friend Don Concannon deserve congratulations: Their robust stand in the defence and support of the Armed Forces and the Royal Ulster Constabulary has been a tonic to Northern Ireland (S5LV0394P0_04209, 06/07/1978).

(12) My right honourable friend the Secretary of State, Tessa Jowell and the Minister my noble friend Baroness Blackstone, are to be congratulated: It is to be widely welcomed and applaueded in its attempt to get to grips with an extremely fast-moving industry: Its ambition and its comprehensiveness are exemplary and I hope and believe, as does my good friend the noble Lord, Lord McNally, that great things will flow from it (S5LV0641P0_01779, 20/11/2002).

Chilton (2004: 46-7) highlights the "identification [of X] as a source of authority", "boasting about performance and positive [...] presentation" (i.e. praise) as three techniques of political legitimisation. This positive presentation/identification need not only be in respect to Self, but can relate to a person who shares the same ideological stance, politically speaking (as above). Other forms of legitimisation include "self-apology, self-explanation, self-justification, [...] reason, vision and sanity, where [once again] the self is either an individual or the group with which an individual identifies or wishes to identify" (Chilton 2004: 47).

\subsubsection{Respect + Contempt + Speech Act}

The converse of legitimisation is delegitimisation. As we have seen (in Section 4.3.1), this often involves negative other-presentation using "ideas of difference and boundaries, [...] acts of blaming, scape-goating, marginalising, excluding, attacking the moral character of some individual or group, attacking the communicative cooperation of the other, [and] attacking the rationality and sanity of the other" (Chilton 2004: 46-7). In Example (13), taken from the dataset representative of the Iraq War period, found using the meaning constellation "respect/ contempt/speech act", a Member of the Lords seems to be countering a previous attempt at delegitimisation:

(13) If I may respectfully say so, the document is neither guff nor nonsense: The provisions are serious stuff indeed for the people who will be subject to them: It is our hope and aspiration that those who will work with us in partnership, and who have worked with us in partnership, will see the fruits of their labour: It does not befit any of us in this Chamber to deride or decry that partnership (S5LV0643P0_02942, 20/01/2003).

Once again, this is achieved using, first, a veil of superficial politeness (If I may respectfully say so) and, then, a counter-argument that "the document is neither guff nor nonsense". Those who would (continue to) suggest so are then delegitimised themselves: via the implicature that, by deriding or 
decrying serious provisions, and the partnership which made such provisions possible, they are behaving in ways that do "not befit [...] this Chamber" (i.e. uncooperatively and inappropriately). The strategy is a particularly interesting one, as it forces any "deriders" who continue to challenge the validity of "the document" to also deal with the negative other-presentation of both undermining a partnership and behaving inappropriately (i.e. in ways that reflect badly upon the Chamber).

The dataset covering much of the period of the Iraq War contained fewer instances of the meaning constellation "respect/contempt/speech act", with the dataset covering the 1812 period giving us the most instances (see Figure 6).

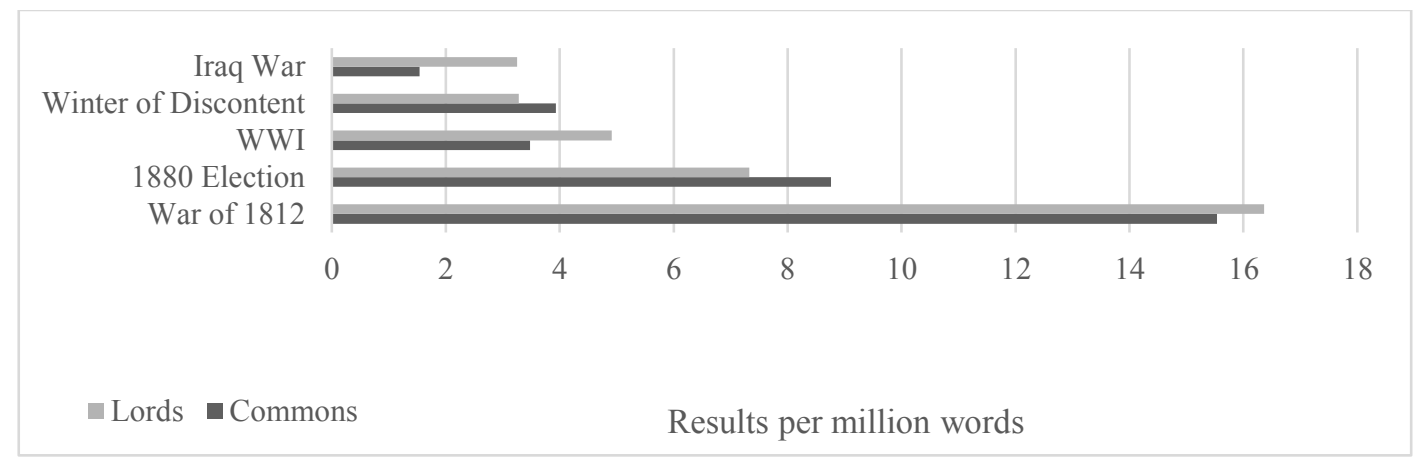

Figure 6. "respect/contempt/speech act" meaning constellation results

Example (14), from the Lords section of the 1812 dataset, draws on deixis and presupposition to frame "what is, and what is not, might be or might not be, 'a bad thing' or 'a good thing"" within the political arena (Chilton 2004: 85):

(14) They are also, I must believe, men far too wise, and of judgments infinitely too enlightened, not to be sensible that if disgrace should attach any where, it must fall on the authors of the calumny, and not on those to whom it is applied (S1V0025P0_00767, 01/12/1812)

Notice that S simultaneously engages in face enhancement and face threat when contrasting wise and enlightened men, who recognise that "authors of [...] calumny" must be the ones held accountable, with those who (by implication) are foolish enough to hold 'innocents' accountable. The asserted representation of reality is thus cleverly intertwined with a moral duty of doing the right thing (see e.g. "it must fall on [...]"). As Chilton $(2004: 64,119)$ notes, it takes effort to retrieve, formulate and challenge such representations of reality, "even when hearers might find them inconsistent with their own representations of reality or find the truth claim faulty". The face-threatening potential of such utterances ensures, in turn, that that effort has a social as well as a cognitive component. 
The notion of acting justly is prevalent in not only parliamentary proceedings captured via (Historic) Hansard transcripts, but also related datasets such as political interviews and political speeches (Chilton, 2004). Like parliamentary proceedings, political interviews and political speeches are also sites where reality is not only represented using language, but contested too. Example (15) (involving the "respect/contempt/speech act" meaning constellation) explicitly seeks to counter assertions made by another, by negatively framing them as being "without any real foundation" and thus intentionally manipulative:

(15) Can they look with respect upon the man who makes these assertions without any real foundation, and tries to lead the people of this country to the belief that these charges represent the general condition of things during that unhappy week in the capital of Ireland? (S5CV0084P0_06839, 26/07/1916).

Contesting another's representation of reality too aggressively within parliamentary proceedings can prove costly, especially when it is deemed to constitute unparliamentary language use. As such, Example (16) contains an apology for such unparliamentary language use, with the MP nonetheless signalling that his view of things remains unchanged - hence his "wish [...] to repeat [his] protest":

(16) I beg most respectfully to apologise to you, Mr: Whitley, for the words I uttered just now, which might seem disrespectful: I have no doubt they were, and I will only answer by saying that I meant no disrespect, and I sincerely regret the remarks I made: I wish, however, to repeat my protest (S5CV0082P0_02362, 10/05/1916).

S's use of second person you (in respect to Mr Whitley), as well as first person $I$, is particularly striking here. Further research would need to determine whether this is a peculiarity of this particular MP, or a peculiarity of apologies (in this setting).

\section{Main insights}

In this paper, we first outlined notions of facework (Section 2), before going on to describe our (Historic) Hansard datasets (1812-2004) and the activity type they represent (Section 3). We then demonstrated three methods of finding potential indicators of face aggression, face enhancement or a combination thereof, and the results gleaned when applied to the Hansard texts. The first method prioritised P-tags traversing two (or more) semantic fields (Section 4.1). The second method prioritised HTOED classifications and HT_codes (Section 4.2). The third method prioritised meaning 
constellations, that is, contiguous tag searches using sequences of named tags (i.e. specific HT_codes, semtags and/or POS-tags: Section 4.3). As Table 1 reveals, all methods highlighted numerous PFIs, which proved to be genuine instances of facework when the utterances captured were checked in context. A particular positive of the three methods is their ability to highlight not only PFIs characterised by evaluative commentary (Sections 4.2-4.3), but also PFIs which are not (Sections 4.3.1-4.3.3). The latter is perhaps even more important than the former, when it comes to the Hansard transcripts, because of the prohibition on using "insulting or rude language" that breaks the chamber's "rules of politeness" or on MPs "misrepresenting each other's words" (http://www.parliament.uk/). Our emphasis on demonstrating how the three methods can find PFIs worthy of further exploration explains the use of single utterances as illustrative examples. We recognise that this might be problematic for some, given the (now) popular theory that it is A who is responsible for the uptake of the message and thus s/he "who assigns politeness" (or lack of) "to any utterance" (Kopytko 1995: 488). We would argue, however, that the "uptake of a message" by A and others, based upon their perceptions of the utterer's intentions, and not "the utterer's original intention" (Locher \& Watts 2008: 80), can sometimes be seen in a single utterance: especially when A becomes $\mathrm{S}$ in a following turn. In Example (13), for instance, a Member of the Lords countered a previous attempt at delegitimisation using delegitimisation strategies of their own (Section 4.3.3). Their approach involved using a veil of superficial politeness (If I may respectfully say so) followed by a counterargument that "the document [was] neither guff nor nonsense". The Member then went on to implicate that the "deriders" were behaving in ways that did "not befit any of us in this Chamber", thereby making their affront not merely an affront to him, but an affront to the Chamber. We return to the important issue of attending to $\mathrm{A}$ as well as $\mathrm{S}$ below, in our discussion of future studies (see Section 6). Suffice it to say, the single utterances drawn upon were able to exemplify politicians' use of (intentional) face threat, (intentional) face enhancement and a combination thereof. They also pointed to discursive moves where any facework intent on the interlocutor's part remained strategically ambiguous (Archer 2015), presumably because of the unparliamentary language prohibition.

Given such results, we believe that, collectively, our three methods have the potential to capture both the extent to which as well as how facework has been used in this political context and, where relevant, changes to facework practices over time and/or according to House (Commons versus Lords). For instance, all methods highlighted incidences of facework that were reliant upon the third person and/or the use of honorifics, be it to 'do' face enhancement or to 'do' face threat (see 4.1-4.3.3, and also Chilton 2004). The few exceptions to this 'rule' seem to involve the performance of specific speech acts such as apologies, using the first and second person (see 4.3.3). In Section 
4.3.2, we highlighted illustrative examples involving conventional respect forms, where the purpose was to congratulate and praise the named MPs, and linked this to Chilton's notion of political legitimisation. In Section 4.1, we discussed how MPs and Members of the Lords will also varnish what are effectively face aggravating acts (Johnson \& Clifford 2011) with these and other expressive politeness features (Eelen 2001): in particular, 'polite' preludes (e.g. with great respect). In some instances, conventional respect forms were interchanged with the more salient (and potentially distancing) third-person he/his (Chilton 2004: 105). In Example (7), for instance, an MP criticised his "hon: Member" for always "throw[ing] cold water upon the stories of atrocities in Belgium", before retorting "why he should always drag in his sneers about the Belgian atrocities ... I leave it for the House and country to judge" (Section 4.3.1). In Section 4.2, we drew upon Example (3), involving President Bush and Genghis Khan, as a means of highlighting the importance of investigating thirdperson face attack - and also third-person face enhancement - which targets another or others who are absent (i.e. not in parliament). Example (3) and Example (9) also reveal how politicians are very often 'doing' "politics in and through their acts of communication" and, as such, can "be seen both to bring their discourse identities as political agents into a communicative setting, and to bring them out in that setting" (Fetzer \& Bull 2012: 128) for impression management purposes. In the case of Example (3), the MP presumably wanted to distance himself (and possibly the party he represented) from Bush's policies in respect to Iraq, whilst simultaneously warning the then "Foreign Secretary and his colleagues" of being too closely allied to the US President. In the case of Example (9), S effectively characterised Toryism (as well as Irishmen) as being attached "to the good old days" to the extent of hampering political progress.

We deliberately included a period close to the Victorian age (1837-1901), as part of our Hansard datasets, based upon the argument that this age, in particular, should offer the perfect reflection of Brown \& Levinson's (1987) politeness model (Culpeper \& Demmen 2011). We have found the 1812 dataset to be somewhat of a "mixed bag", however. The prevalence of more faceenhancement strategies in this dataset, compared with other datasets, is very much in line with Culpeper \& Demmen's (2011: 51) claim that the Victorian politeness “culture [actually] began evolving a few decades before" the Victorian Age proper. Yet, the same dataset also contained more frequencies of face-aggravating strategies than the other datasets: including the "speech and hatred" meaning constellation (see 4.3). Further research is needed to explain the use of the greater range of facework in this period (and often in higher frequencies). What we can state, at this point, is that the incidences of facework identified by our three methods (across all datasets) suggest that MPs (and Lords) of times past definitely acted in similar ways to Brown \& Levinson's (1987) notion of a rational agent (as they do today): in the sense of purposely choosing their facework strategies. This 
said, the facework we have uncovered was not typically seeking to mitigate or compensate for FTAs (by, e.g., S doing work to protect A's face when FTAs are likely to occur). Rather, MPs of the past opted for face aggravating discursive moves (as well as face enhancing discursive moves) - especially when debating in parliament. Such a pattern was also replicated in the modern-day datasets (see 4.14.3.3). Typical moves involved making points (Goffman 1967), building or countering representations of reality (Chilton 2004), intentionally and explicitly engaging in face-threatening (as well as) face-enhancing acts (Harris 2001), and/or putting pressure on A in other more implicit ways (Wierzbicka 2006). As discussed above, the threat of being found to have used unparliamentary language tended to ensure that politicians of times past were also as linguistically creative as politicians are today. This may help to explain the pervasiveness of strategically-ambiguous facework in all of our Hansard datasets. It would suggest, in turn, that the discourse within today's "Prime Minister's Question Time" is possibly more "explicitly face threatening [...] adversarial and confrontational" than other parliamentary debates (cf. Harris 2001: 451).

\section{Future work}

The tendency of MPs and Members of the Lords to purposely choose a face-enhancing and/or faceaggravating discursive move means that our reliance on single utterances as illustrative examples (which illuminate our PFI findings) is not as problematic as some might suppose. However, in future work, we will be exploring the dynamics between S and A in much more detail. Given the strategic goals of MPs and Lords, when interacting together in parliament or the Chamber, we are particularly keen to determine A's role in shaping S's turn: in line with the theory that it is A "who assigns politeness" (or lack of) "to any utterance" (Kopytko 1995: 488). Although we can (re)construct perceptions of intentions from a single utterance (as addressees must do within their own interactions), there is much to be gained by assessing PFIs in their context, not least because it will help us to see the relational work indiviuals engaged in when negotiating relationships with others in this parliamentary setting (Locher \& Watts 2008: 78). Chilton's (2004) discussion of parliamentary language - in particular, his discussion of repairs needed when turn-taking rules are apparently flouted and/or political opponents clash - may prove particularly useful in this regard. We will be undertaking detailed explorations of the differences between the Commons and Lords when it comes to facework as part of this work, as a means of determining the extent to which such differences relate to their differing roles. As such, we are particularly keen to establish the shaping effects of any intended and unintended overhearer(s), such as the general public, other governments, etc., as well as any social, 
ideological and/or cultural 'norms' in play, which may serve to colour a particular parliamentary debate at a particular time. This will necessitate the kinds of detailed review of the issues surrounding a debate (like fighting a 'just' war, or dealing with a refugee crisis caused by ongoing wars in other countries), in which Chilton (2004) engages, as well as a sense of what the politicians regarded to be common or shared knowledge at the time. A focus upon the social, ideological and/or cultural 'norms' in play will also enable us to better appreciate when MPs and Members of the Lords are speaking for themselves, and when they are speaking for their party (and how this affects their representation of reality, facework, impression management strategies, etc.).

\section{Acknowledgements}

The work reported here was made possible, via AHRC/ESRC funding for the SAMUELS project (grant reference $\mathrm{AH} / \mathrm{LO} 1 \mathrm{OO} 62 / 1)$. Our thanks also go to the anonymous reviewers of this paper, as well as the editors of the journal, whose comments have helped to strengthen this paper greatly. Any remaining infelicities are ours.

\section{Notes}

1. For a detailed explanation of Wmatrix3, see http://ucrel.lancs.ac.uk/wmatrix/.

2. HTST was developed as part of the cross-university, AHRC/ESRC funded, SAMUELS project (grant reference $\mathrm{AH} / \mathrm{LO} 1 \mathrm{OO} 62 / 1)$.

3. This is possible thanks to a number of dictionaries, phonetic matching, an edit distance metric, letter replacement heuristics and statistical models.

4. Parliamentary reporting precedes Hansard and, hence, the nineteenth century.

5. The current system of publishing transcripts from the House of Lords separately to transcripts from the House of Commons was also established in 1909.

6. Our interest in impression management as well as facework (and the links between them) further explains our opting to investigate times when politicians are known to have debated issues of emotional (as well as political) import. Emotion is an important component of both impression management and facework. For example, Jones \& Pittman (1982: 238) differentiate impression management strategies according to the emotion they arouse (e.g. intimidation tends to evoke discomfort and potentially fear). Similarly, Culpeper 
(2011: 21) makes emotion "a central part of [his] definition of impoliteness" (because of the "emotional consequences" that impolite acts have for the Target). See also the work of Goffman $(1959,1967)$.

7. We have been somewhat conservative when distinguishing true from false positives, especially given some researchers "accept that facework is always present in any form of socio-communicative verbal interaction" (Locher \& Watts 2008: 96).

8. The HT_codes included here should not be taken to be completely representative. Rather, the purpose of the Table is to provide the reader with a flavour of the types of HT themes, which might point to potential facework in this political context.

\section{References}

Archer, D. (2015). Slurs, insults, (backhanded) compliments and other strategic facework moves. Language Sciences 52, 82-97.

Archer, D. (2014). Exploring verbal aggression in English historical texts using USAS: The possibilities, the problems and potential solutions. In I. Taavitsainen, A. H. Jucker \& J. Tuominen (Eds.), Diachronic Corpus Pragmatics, (pp. 277-301). Amsterdam/Philadelphia: John Benjamins.

Baron, A., \& Rayson, P. (2008, May). VARD 2: A tool for dealing with spelling variation in historical corpora. Paper presented at the Postgraduate Conference in Corpus Linguistics, Birmingham, UK.

Baumeister, R. F. (1987). How the self became a problem: A psychological review of historical research. Journal of Personality and Social Psychology, 52(1), 163-76.

Brown, P., \& Levinson, S. C. (1987). Politeness. Some Universals in Language Usage. Cambridge: Cambridge University Press.

Chilton, P. (2004). Analysing Political Discourse: Theory and Practice. London/New York: Routledge.

Cockcroft, R., \& Cockcroft, S. (2005). Persuading People: An Introduction to Rhetoric (2nd. ed.). Basingstoke/New York: Palgrave Macmillan.

Crewe, E. (2005). Lords of Parliament: Manners, Rituals and Politics. Manchester University Press: Manchester.

Culpeper, J. (2011). Impoliteness: Using Language to Cause Offence. Cambridge: Cambridge University Press.

Culpeper, J., \& Demmen, J. (2011). Nineteenth-century English politeness: Negative politeness, conventional indirect requests and the rise of the individual self. In M. Bax \& D.Z. Kádár (Eds.), Understanding Historical (Im)politeness (pp.49-80). Amsterdam/Philadelphia: John Benjamins.

Dunning, T. (1993). Accurate methods for the statistics of surprise and coincidence. Computational Linguistics, 19(1), 61-74.

Eelen, G. (2001). A Critique of Politeness Theories. Manchester: St. Jerome's Press. 
Farrelly, M., \& Seoane, E. (2012). Democratization. In T. Nevalainen \& E. C. Traugott (Eds.), The Oxford Handbook of The History of English (pp.392-401). Oxford: Oxford University Press.

Fetzer, A., \& Bull, P. (2012). Doing leadership in political speech: Semantic processes and pragmatic inferences. Discourse \& Society, 23(2), 127-144.

Finch, E., \& Fafinski, S. (2015). Legal Skills. Oxford: Oxford University Press.

Goffman, E. (1959). The Presentation of Self in Everyday Life. Garden City, NY: Doubleday/Anchor.

Goffman, E. (1967). Interaction Ritual: Essays on Face-to-Face Behavior. Garden City, NY: Anchor Books.

Harris, S. (2001). Being politically impolite: Extending politeness theory to adversarial political discourse. Discourse \& Society, 12(4), 451-472.

Johnson, A., \& Clifford, R. (2011). Polite incivility in defensive attack: Strategic politeness and impoliteness in cross-examination in the David Irving vs. Penguin Books Ltd and Deborah Lipstadt trial. Journal of Politeness Research: Language, Behaviour, Culture, 7(1), 43-71.

Jones, E. E., \& Pittman, T. S. (1982). Toward a general theory of strategic self-presentation. In J. M. Suls (Eds.), Psychological Perspectives of the Self (pp.231-62). Hillsdale, NJ: Erlbaum.

Jucker, A. H. (2012). Changes in politeness cultures. In T. Nevalainen \& E. C. Traugott (Eds.), The Oxford Handbook of The History of English (pp.422-433). Oxford: Oxford University Press.

Jucker, A. \& Taavitsainen, I. (2000). Diachronic speech act analysis: Insults from flyting to flaming. Journal of Historical Pragmatics, 1(1), 67-95.

Kopytko, R. (1995) Against rationalistic pragmatics. Journal of Pragmatics, 23, 475-91.

Leech, G. N., Hundt, M., Mair, C., \& Smith, N. (2009). Change in Contemporary English: A Grammatical Study. Cambridge: Cambridge University Press.

Levinson, S. C. (1992). Activity types and language. In P. Drew \& J. Heritage (Eds.), Talk at Work: Interaction in Institutional Settings (pp.66-100). Cambridge: Cambridge University Press.

Locher, M., \& Watts, R. (2008). Relational work and impoliteness: Negotiating norms of linguistic behaviour.

In D. Bousfield \& M. Locher (Eds.), Impoliteness in Language: Studies on its Interplay with Power in Theory and Practice (pp.77-100). Berlin/New York: Mouton de Gruyter.

May, E., \& Sweetman, J.F. (Eds.) (1989). Erskine May's Treatise on the Law, Privileges, Proceedings and Usage of Parliament (21st ed.) London: Butterworths.

Penman, R. (1990). Facework \& politeness: Multiple goals in courtroom discourse. Journal of Language and Social Psychology, 9(1/2), 15-38.

Rayson, P. (2008). Wmatrix: A Web-based Corpus Processing Environment [Computer software]. Lancaster: Lancaster University. Available at http://ucrel.lancs.ac.uk/wmatrix/.

Reid, C. (2012). Imprison'd Wranglers: The Rhetorical Culture of the House of Commons 1760-1800. Oxford: Oxford University Press.

Smiles, S. (1859). Self-Help; with Illustrations of Character and Conduct. London: John Murray.

Trilling, L. (1967). Beyond Culture: Essays on Literature and Learning. Harmondsworth: Penguin.

Ward, J. (1980). The Hansard Chronicles. Toronto: Deneau and Greenberg. 
Watts, R. J. (2003). Politeness. Cambridge: Cambridge University Press.

Wenger, E. (1998). Communities of Practice: Learning, Meaning and Identity. Cambridge: Cambridge University Press.

Wierzbicka, A. (2006). Anglo scripts against "putting pressure" on other people and their linguistic manifestations. In C. Goddard (Ed.), Ethnopragmatics. Understanding Discourse in Cultural Context (pp. 31-63). Berlin: Mouton de Gruyter. 